\title{
500 ANOS DE LUTAS SOCIAIS NO BRASIL: movimentos sociais, ONGs e terceiro setor
}

Maria da Glória Gohn

\section{MOVIMENTOS SOCIAIS: O CONCEITO}

Apesar do número razoável de estudos específicos sobre a problemática dos movimentos sociais, não podemos afirmar que existam teorias bastante elaboradas a seu respeito. Parte dessa lacuna é dada pela multiplicidade de interpretações e enfoques sobre o que são movimentos sociais. Um conjunto díspar de fenômenos sociais tem sido denominado como movimentos sociais. Na tentativa de clarificar a questão criaram-se novas taxinomias ou tipologias empíricas sem fundamentação teórica.

No cenário do mundo globalizado, vários autores têm destacado que o conflito social mudou, no mundo moderno, da esfera da produção para a esfera dos problemas da cultura, e nesta, os problemas de identidade cultural seriam os mais importantes, gerando movimentos em torno das questões de raça, gênero, nacionalidade etc. Outros, como o ex-líder estudantil francês e atual parlamentar do Partido Verde, Daniel Cohn-Bendit, reconhecem a importância dos conflitos culturais, mas atribuem uma determinação econômica àqueles conflitos. Resulta que temos dois "modelos" de análise: um culturalista (enfatizando os movimentos sociais), e outro classista (enfatizando mais as estruturas econômicas, as classes sociais, as contradições sociais e os conflitos de classes). Defendemos uma terceira posição, que destaca a importância da cultura na construção da identidade de um movimento social, mas concebe os movimentos segundo um cenário pontuado por lutas, conflitos e contradições, cuja origem está nos problemas da sociedade dividida em classes, com interesses, visões, valores, ideologias e projetos de vida diferenciados. Entendemos que a análise sobre os movimentos sociais não pode ser separada da análise de classe social, mas também não podemos resumir os movimentos a algo determinado pelas classes. 
Para definir movimento social devemos estabelecer algumas diferenças. Uma primeira, é entre movimentos e grupos de interesses. Interesses comuns de um grupo é um componente de um movimento, mas componente não suficiente para caracterizá-lo como tal. Primeiro, porque a ação de um grupo de pessoas tem que ser qualificada por uma série de parâmetros para ser um movimento social. Este grupo tem que formar um coletivo social e, para tanto, necessita ter uma identidade em comum. Ser negro, mulher, defender as baleias, ou não ter teto para morar, são adjetivos que qualificam um grupo dando-lhe objetivos comuns para a ação. Mas eles têm uma realidade anterior à aglutinação de seus interesses. Eles têm uma história de experiências culturais. As inovações culturais, econômicas ou outro tipo de ação que vierem a gerar, partem do substrato em comum das carências ou demandas que reivindicam, articuladas pelos legados da herança cultural que possuem. A partir dessa base, eles criam e renovam seus repertórios de ações, idéias, valores etc.

Uma segunda diferença deve ser feita quanto ao uso ampliado da expressão ao se designar a ação histórica de grupos sociais, tais como o movimento da classe trabalhadora. Aqui se trata de uma categoria da dialética, a de movimento, em oposição à estática. É a ação da classe em movimento e não um movimento específico da classe. Esta diferença possibilita demarcar dois sentidos para o termo movimento: um ampliado e geral, outro restrito e específico.

Uma terceira diferença deve ser feita entre modos de ação coletiva e movimento social propriamente. Um protesto (pacífico ou não), uma rebelião, uma invasão, uma luta armada, são modos de estruturação de ações coletivas; poderão ser estratégias de ação de um movimento social, mas sozinhos não são movimentos sociais.

Finalmente, uma quarta diferença refere-se à esfera onde ocorre a ação coletiva. Trata-se de um espaço não-institucionalizado, nem na esfera pública nem na esfera privada. Mas devemos tomar cuidado com as generalizações empíricas, denominando de movimento tudo que estiver na esfera não-institucional. Os espaços coletivos nãoinstitucionalizados situam-se na esfera pública não-governamental, ou não-estatal, possibilitando aos movimentos dar visibilidade às suas ações.

Do exposto até o momento podemos tirar uma primeira dedução, a saber: movimento social refere-se à ação dos homens na história. Esta ação envolve um fazer - por meio de um conjunto de práticas sociais 
— e um pensar - por meio de um conjunto de idéias que motiva ou dá fundamento à ação. Trata-se de uma práxis, portanto.

As lutas sociais conferem aos movimentos um caráter cíclico. Eles são como as ondas e as marés; vão e voltam segundo a dinâmica do conflito social, da luta social, da busca do novo ou da reposição/ conservação do velho. Esses fatores conferem às ações dos movimentos caráter reativo, ativo ou passivo. Não bastam as carências para haver um movimento. Elas têm que se traduzir em demandas, que por sua vez poderão se transformar em reivindicações, através de uma ação coletiva. O conjunto deste processo é parte constitutiva da formação de um movimento social. Os fatores carências, legitimidade da demanda, poder político das bases, cenário conjuntural do país darão a força social de um movimento, gerando o campo de forças do movimento social e uma dada cultura política.

Devemos lembrar também que muitos dos chamados "novos movimentos sociais", abrangem dimensões subjetivas da ação social, relativas ao sistema de valores dos grupos sociais, não-compreensíveis para análise à luz apenas das explicações macroobjetivas, como usualmente é tratada a questão das carências econômicas. Trata-se de carências de outra ordem, situadas no plano dos valores, da moral.

A partir das considerações acima formulamos uma definição ampla para o conceito de movimento social, a saber:

Movimentos sociais são ações coletivas de caráter sociopolítico, construídas por atores sociais pertencentes a diferentes classes $e$ camadas sociais. Eles politizam suas demandas e criam um campo político de força social na sociedade civil. Suas ações estruturam-se a partir de repertórios criados sobre temas e problemas em situações de conflitos, litígios e disputas. As ações desenvolvem um processo social e político-cultural que cria uma identidade coletiva ao movimento, a partir de interesses em comum. Esta identidade decorre da força do princípio da solidariedade e é construída a partir da base referencial de valores culturais e políticos compartilhados pelo grupo.

Os movimentos geram uma série de inovações nas esferas pública e privada, participando direta ou indiretamente da luta política de um país e contribuindo para o desenvolvimento e transformação da sociedade civil e política.

Os movimentos aglutinam bases demandatárias, assessores e lideranças e têm estreitas relações com uma série de outras entidades 
sociopolíticas como partidos e facções políticas — legais ou clandestinas —, igrejas, sindicatos, ONGs - nacionais e internacionais -, setores da mídia e atores sociais formadores de opinião pública, universidades, parlamentares municipais, estaduais e federais; setores da administração governamental; e até pequenos e médios empresários etc., articulados em redes sociais com interesses comuns.

É necessário destacar que a temática da solidariedade não significa que os movimentos sejam internamente harmoniosos ou homogêneos. Ao contrário, o usual é a existência de conflitos e tendências internas. Mas, a forma como eles se apresentam no espaço público, o discurso que elaboram, as práticas que articulam nos eventos externos, criam um imaginário social de unicidade, uma visão de totalidade.

A solidariedade é o princípio que costura as diferenças internas fazendo com que a representação simbólica construída e projetada para o outro - não-movimento - seja coerente e articulada em propostas que encobrem essas diferenças, apresentando-se, usualmente, de forma clara e objetiva. Para tal é preciso que se observem os códigos políticoculturais expressos nas reivindicações dos movimentos (apresentados nas linguagens de seus discursos e falas e nos documentos que constroem). São estes códigos que sistematizam as demandas e criam representações sobre elas. A forma como as demandas são codificadas varia segundo a cultura política local, ou seja, segundo o repertório das tradições culturais e as forças sociopolíticas de uma dada conjuntura histórica onde o movimento está ocorrendo.

Em relação aos tipos, podemos ter movimentos de diferentes classes e camadas sociais. O tipo de ação social envolvida é que será o indicador do caráter do movimento. Podemos ter movimentos transformadores, reformistas, redentores e alternativos. Giddens (1993) aglutina os movimentos entre as ações que são geradas por tensões estruturais (movimentos dos negros), crenças generalizadas (movimentos dos direitos civis), distúrbios e violências (movimentos de rua, quebraquebras etc.) e movimentos que são deflagrados por situações de controle social (movimento contra as reformas da Constituição brasileira, exemplificamos nós). Os movimentos são vistos por Giddens como respostas a estímulos externos.

Touraine (1989), sem se preocupar com a criação de uma tipologia, apresenta um leque maior de registros históricos de movimentos 
sociais, subdividindo-os em messiânicos, camponeses, de defesa comunitária, de defesa da identidade, lutas urbanas, novos movimentos sociais, movimentos históricos, movimentos políticos e lutas culturais.

\section{MOVIMENTOS E CLASSES SOCIAIS NO BRASIL}

Desde os tempos do Brasil Colônia, a sociedade brasileira é pontilhada de lutas e movimentos sociais contra a dominação, a exploração econômica e, mais recentemente, contra a exclusão social. A memória histórica registra lutas de índios, negros, brancos e mestiços pobres que viviam nos vilarejos, e brancos pertencentes às camadas médias influenciados pelas ideologias libertárias, contra a opressão dos colonizadores europeus. (vide Gohn,1995; Silveira, 1993; Souza \& Machado, 1997; Paoli, 1995; Chiavenato, 1988 e outros)

A maioria das lutas e movimentos no Brasil Colônia foi empreendida por negros escravos e pela plebe, vulgo "ralé". Eram os indivíduos pobres e livres. A categoria "povo" na época colonial era dada aos comerciantes e artesãos. No topo da pirâmide social estavam os senhores de engenho, os militares e funcionários graduados e o clero. Eles eram seguidos pelos lavradores, grandes mercadores e artesões. Os pobres livres eram os penúltimos, pois os últimos eram os cativos, os escravos. Eis uma lista das lutas mais famosas no Brasil Colônia e na fase do Império: Zumbi dos Palmares (1630-1695), Inconfidência Mineira (1789), Conspiração dos Alfaiates (Minas, 1798), Revolução Pernambucana (1817), Balaiada (Maranhão, 1830-1841), Revolta dos Malés (Bahia, 1835), Cabanagem (Pará, 1835), Revolução Praieira (Pernambuco, 1847-1849), Revolta de Ibicaba (Estado de São Paulo, 1851), Revolta de Vassouras (Estado do Rio, 1858), Quebra-Quilos (Pernambuco, 1873), Revolta Muckers (Rio Grande do Sul, 1874), Revolta do Vintém (Rio de Janeiro, 1880), Canudos (Bahia, 1874-1897, massacrada pelas forças da República). Estes são alguns dos exemplos mais conhecidos até o século XX.

No início deste século a questão social mudou com o advento da República e com a substituição da mão-de-obra escrava pela assalariada, composta massivamente pelos imigrantes. As classes dominantes eram as mesmas elites agrárias vinculadas à burguesia inglesa, hegemônica no período. Mas o modo de produção se altera com a incipiente 
industrialização e a formação de um proletariado urbano. Com ele surgem as organizações de luta e resistência dos trabalhadores expressas em ligas, uniões, associações de auxílio mútuo etc.

Nas duas primeiras décadas do século ocorreram revoltas da população reivindicando serviços urbanos, ou protestando contra políticas locais como a Revolta da Vacina (Rio de Janeiro, 1905), Revolta da Chibata (Rio de Janeiro, 1910), Revolta do Contestado (Paraná, 1912), ligas contra o analfabetismo (1915), ligas nacionalistas pelo voto secreto e expansão da educação (1917), revoltas contra o preço do pão, por feiras livres, contra a inspeção de bagagens nas estações de trens, contra a colocação de trilhos para os bondes (que retiravam o emprego dos carroceiros e quebravam os cascos das patas de seus cavalos), atos contra o desemprego e a carestia em São Paulo e no Rio de Janeiro etc.

No início do século a classe operária morava em vilas construídas pelos donos das fábricas (uma forma de reduzir e controlar o preço da mão-de-obra) ou nos cortiços e favelas (também chamadas de cabeças de porco). As condições de moradia eram um espelho das condições de trabalho. Inúmeras greves e revoltas ocorreram, destacando-se a greve de 1917 em São Paulo e a Revolta da Chibata, da armada naval brasileira, que se iniciou no Rio de Janeiro e se espalhou para vários pontos do país.

Nos anos 20 surgem várias lutas e movimentos das camadas médias da população urbana e revoltas de militares, bem como movimentos messiânicos e de cangaceiros no sertão nordestino do país, como o liderado pelo padre Cícero no Ceará (1926) e por Lampião na Bahia (1925-1938). Nas cidades destacaram-se a Revolução dos Tenentes (1822), a Coluna Prestes, as lutas pela educação desenvolvidas pelos reformadores (Anísio Teixeira, Fernando de Azevedo e outros).

O movimento articulado pelas elites que ficou conhecido como Revolução de 30 demarca um novo tempo no país, em termos de consolidação de novas regras que buscavam inseri-lo no cenário internacional, não apenas como produtor de produtos agrícolas, mas também como produtor de bens de consumo industrializados (têxtil e mobiliário) e gêneros alimentícios de primeira necessidade. Surgem condições para o desenvolvimento de uma classe burguesa industrial. A classe operária muda de composição: de imigrantes estrangeiros para os migrantes nacionais, egressos do campo para a cidade. O Estado assume a liderança do processo de desenvolvimento nacional e promulga uma série de leis, destacando-se a legislação do trabalho. Ministérios e 
secretarias foram criados e a questão social, até então objeto apenas da ação da polícia, passa a ter a atenção de setores específicos dos governos.

Vários movimentos sociais ocorreram no período de 1930-1937, entre os quais o Movimento dos Pioneiros da Educação (1931), a Marcha Contra a Fome (1931), a Revolução Constitucionalista de São Paulo (1932), a Revolta do Caldeirão no Ceará (1935), a criação da Aliança Libertadora Nacional (1935), o Movimento Pau de Colher (ocupação de terras na Bahia, em 1935), revoltas militares etc. O golpe do Estado Novo em 1937, impetrado pelo ex-presidente Getúlio Vargas, amorteceu os conflitos sociais pelo controle via repressão. A partir de 1942 são criadas várias sociedades amigos de bairros, frutos da expansão do processo de urbanização nas principais capitais do país.

O período entre 1945 e 1964 entrou para a história como a fase do regime político populista; ele foi bastante fértil em termos de lutas e movimentos sociais. A conjuntura de redemocratização do país, aliada a um cenário internacional de desenvolvimento da sociedade de consumo, e a política da Guerra Fria entre as então potências mundiais (Estados Unidos e URSS - a ex-União das Repúblicas Socialistas Soviéticas) criaram espaços favoráveis aos projetos nacionalistas de desenvolvimento nacional. O Estado altera suas políticas e passa a criar condições para a instalação de indústrias multinacionais no país. Inicialmente, desenvolve políticas para o setor de energia, cria a Petrobrás; estradas, silos, armazéns, portos e usinas hidrelétricas são patrocinados pelo Estado. Constrói-se Brasília e inauguram-se as primeiras fábricas de automóveis. Um novo setor da classe operária surge no $A B C D$ paulista: os metalúrgicos. Setores da burguesia industrial brasileira fizeram alianças com capitalistas internacionais.

Entre 1961-1964 eclodiram centenas de greves no país. Criaramse, no campo, dois movimentos que são considerados como os antecessores dos atuais sem-terra: as Ligas Camponesas do Nordeste e o Movimento dos Agricultores Sem-Terra (MASTER), no Sul do país. $\mathrm{Na}$ área da educação criou-se o Movimento de Educação de Base (MEB). Setores da área da educação e da cultura aliaram-se aos grupos que lutavam por um projeto de desenvolvimento nacional autônomo e produziram vários eventos, publicações e movimentos, como os Círculos Populares de Cultura (CPC) da União Nacional dos Estudantes (UNE). O sindicalismo industrial viveu grandes conflitos, tanto internos - entre os sindicatos oficiais e o sindicalismo paralelo, de oposição - como 
externos - gerados nos embates com os proprietários das empresas e com o Ministério do Trabalho.

O golpe militar de 1964 pôs fim a um ciclo de mobilização e organização popular. Entre 1964 e 1969 os movimentos de resistência foram poucos. No meio industrial ficaram famosas as greves de Contagem (MG) e Osasco (SP). Os estudantes, influenciados pela conjuntura nacional e internacional - principalmente o Maio de 68 na França e a política cultural maoísta na China - entraram para a história como novos atores em cena, naquele período. O Estado redefiniu suas leis e criou novos aparelhos burocráticos de controle. O Ato Institucional $\mathrm{n}^{2} 5$, de dezembro de 1968 , cassando e punindo pessoas e estabelecendo severas restrições aos direitos sociopolíticos dos cidadãos, foi o ponto culminante de uma era de medo, repressão e violação dos direitos humanos, comandada por regimes militares que se espalhariam por toda América Latina.

Com o regime militar no poder, a esquerda partiu para a luta armada e seus principais líderes foram mortos nos embates das "guerrilhas". As camadas médias da população brasileira se expandiram e se locupletaram com as benesses que o regime lhes oferecia: expansão do ensino superior (pago), acesso ao consumo de bens industrializados, principalmente a linha branca doméstica, os televisores e os carros. Criou-se um banco para financiar a casa própria: o Banco Nacional da Habitação (BNH). As camadas médias tiveram acesso ainda aos novos empregos gerados pelas multinacionais que aqui se instalaram e aos cargos na burocracia governamental. Foi a fase da tecnocracia, do planejamento centralizado. A classe operária sofreu um grande arrocho salarial.

A partir de 1974, com a crise internacional do petróleo, o chamado "milagre brasileiro" entra em crise. A resistência ao regime militar começa a se articular. Os movimentos sociais emergem das cinzas. Nas cidades, as Comunidades Eclesiais de Base(CEBs), embaladas pela Teologia da Libertação, ${ }^{1}$ organizaram milhares de pessoas e deram origem a movimentos populares vigorosos como Custo de Vida (depois Carestia), movimentos pelos transportes, de favelados pelo direito real de uso da terra onde estavam, pela saúde nos centros e postos comunitários de saúde, por vagas nas escolas etc. Grande parte desses movimentos serviu de base de apoio às greves que se espalharam pelo país entre 1978-1979. Eles formaram os comitês de compra de gêneros de primeira necessidade e de apoio aos operários em greve. 
O setor da educação também se mobilizou e surgiram várias associações e uniões de trabalhadores do ensino (tanto do antigo $1^{\circ} \mathrm{e}$ $2^{\circ}$ graus, como do ensino universitário). $\mathrm{O}$ ciclo de greves dos trabalhadores declina após a reforma que pôs fim ao bi-partidarismo no país com a retomada do processo eleitoral em âmbito estadual. Os trabalhadores recriam suas centrais sindicais a partir da Associação Nacional de Movimentos Populares e Sindicais (ANAMPOs). Surge a Confederação Geral dos Trabalhadores (CGT) e a Central Única dos Trabalhadores (CUT).

No campo popular foi criada a Confederação Nacional das Associações de Moradores (CONAM) e a ANAMPOS continuou a aglutinar os setores populares mais próximos das práticas sociais da CUT, do Partido dos Trabalhadores e dos setores progressistas da Igreja Católica. Posteriormente a ANAMPOS se transforma em Pró-Central dos Movimentos Populares, que deu origem à Central dos Movimentos Populares em 1993.

O ano de 1984 foi um marco na história sociopolítica do Brasil com o movimento Diretas Já. Foi a declaração de morte do regime militar. Mas as eleições diretas para presidente da República só vieram a acontecer em 1989. Entre 1984 e 1988 o país se mobilizou por uma nova Constituição. Os movimentos sociais que emergiram na cena política, desde o final dos anos 70 , conseguiram inscrever em leis, como direitos, várias reivindicações. Foram conquistas sociais de trabalhadores, mulheres, índios, menores e cidadãos até então considerados como de "segunda categoria".

Mas a crise internacional do capitalismo globalizado já havia se espalhado pelo planeta e atingiu o Brasil nos anos 90. Desemprego, reformas, reestruturações no mercado de trabalho, flexibilização dos contratos etc. passaram a ser a tônica do novo cenário. Os sindicatos dos trabalhadores se enfraqueceram, o número de pessoas a atuar na economia informal multiplica-se centenas de vezes. Os sindicatos passam a lutar contra as políticas de exclusão social do governo; muda-se a pauta das reivindicações dos trabalhadores: a luta é para manter o emprego e não por melhores salários ou condições de trabalho, como na fase anterior. Os movimentos sociais populares urbanos se desarticulam. A luta social no campo recrudesce e o Movimento dos Trabalhadores Rurais Sem-Terra (MST), criado nos anos 80, ganha as manchetes da mídia e torna-se o agente do principal conflito social no 
país. Os movimentos de resistência às reformas na Constituição nacional foram tímidos e não conseguiram alterar o quadro de correlação de forças. (Gohn, 1997b)

Novamente as camadas médias tiveram um peso decisivo no apoio ao regime político prevalecente. O plano de estabilização econômica lastreado no Real e na quase paridade com o dólar americano, vigente de julho de 1994 a janeiro de 1999, fundamentou as expectativas de mudanças em direção à modernidade, um valor básico para aquelas camadas. Contudo, as alterações na política econômica ocorridas em janeiro de 1999 levaram a mudanças no estilo de vida das diferentes classes e camadas sociais brasileiras; fim da era do consumo fácil de importados pelas camadas médias, aprofundamento da recessão e recrudecimento das taxas de desemprego. As reformas administrativas do Estado agravaram a instável estabilidade dos funcionários públicos. Entretanto, o cenário político-econômico é outro. Novos atores entraram em cena; desta vez não para lutar contra a exclusão clamando por cidadania e direitos sociais, mas lutando pela inclusão, pela integração dos excluídos que o sistema gera. Trata-se do contraditório terceiro setor, que passaremos a analisar a seguir.

$\mathrm{O}$ ano de 2000 marca o retorno dos movimentos sociais à cena política nacional. ${ }^{2}$ Apesar de quase uma década de desmobilização dos movimentos populares urbanos, eles iniciam lenta retomada, em outras bases, incorporando a experiência adquirida via a participação nos conselhos, fóruns e outras formas mais ou menos institucionalizadas de participação. Entretanto, outros movimentos sociais ganham as manchetes da mídia, como o dos índios. Eles se reorganizaram em função da luta pela demarcação de suas terras, realizaram marchas e caminhadas e aproveitaram a conjuntura política em torno da polêmica questão dos "500 anos de descobrimento do Brasil" para protestar e exigir seus direitos. Foram reprimido pelas forças policiais e ganharam a simpatia e o apoio de governos e organismos internacionais, que se manifestaram contra a violência cometida. O MST ganha novo fôlego e se alastra por todo Brasil. Os estudantes voltaram às ruas, não mais com as "caraspintadas". Voltaram politizados em luta contra o desemprego e a corrupção. As greves dos professores - em diversos graus do ensino - também retornam. E outras categorias passam a se organizar e a protestar, como os caminhoneiros das estradas contra as taxas dos pedágios e suas péssimas condições de trabalho; os "perueiros" 
(transporte coletivo urbano alternativo) pela igualdade nas condições de trabalho com os transportes convencionais etc."

\section{A EMERGÊNCIA DE NOVAS FORMAS DE ASSOCIATIVISMO E O TERCEIRO SETOR NOS ANOS 90}

\subsection{Origem e Composição}

No Brasil, nos anos 90, existem inúmeras organizações, fundações, associações, movimentos etc. criados para promover o desenvolvimento econômico local, impedir a degradação ambiental, defender os direitos civis e atuar em áreas onde o Estado é incipiente, como em relação aos idosos, à mulher, aos índios, aos negros etc.; assim como para atuar em áreas onde a presença estatal é de triste memória, como em relação às crianças, em internatos ou nas ruas em situação de risco, vítimas de todo tipo de violência. Essas categorias sociais, até então esquecidas, isoladas e desconsideradas, passaram a exercitar o que a sociedade conquistou: o direito a ter direitos. A organização inicial desses segmentos sociais se deu nos anos 80 por meio das ações de movimentos e organizações de lutas por direitos. Eles criaram uma pauta de reivindicações que se transformou em leis, criando uma nova juridização para o social e inúmeros canais de interlocução com o Estado via conselhos gestores, câmaras etc. Participando destes canais, como representantes da sociedade civil, encontramos um universo grande de organizações, movimentos sociais, ONGs, associações comunitárias de vizinhança, fundações, entidades filantrópicas, "empresas cidadãs" etc. que compõem o chamado "terceiro setor".

Nosso ponto de partida para o entendimento do terceiro setor é também nosso postulado fundamental: trata-se de um fenômeno complexo, diferenciado e contraditório. Ele tem gerado um tipo de associativismo que atua no nível do poder local e suas organizações se definem com fins públicos sem fins lucrativos. A natureza do terceiro setor foi construída nos últimos anos a partir de transformações no campo das ONGs, dos movimentos sociais e das associações filantrópicas e comunitárias. A origem dessas transformações advém tanto de alterações

- Parágrafo acrescentado pela autora no processo de revisão. (N. da C.E.)

Rev. Mediações, Londrina, v. 5, n. 1, p. 11-40, jan./jun. 2000 
amplas, ocorridas internacionalmente no mundo da economia e da política, como de fatores no nível nacional, advindas de alterações no cenário da sociedade civil brasileira, especialmente na organização popular, em mobilizações e participação popular direta, nas décadas de 70 e 80 , geradoras de inúmeras ações que vieram a se constituir um grande acervo de experiência acumulada. As transformações das ONGs são também resultado das estratégias políticas contidas nas novas políticas sociais dos Estados e governos nacionais, nos anos 90 .

Por tudo isso o terceiro setor é um tipo "Frankenstein": grande, heterogêneo, construído de pedaços, desajeitado, com múltiplas facetas. É contraditório, pois inclui tanto entidades progressistas como conservadoras; abrange programas e projetos sociais que objetivam tanto a emancipação dos setores populares e a construção de uma sociedade mais justa, igualitária, com justiça social, como programas meramente assistenciais, compensatório, estruturados segundo ações estratégicoracionais pautadas pela lógica do mercado. Um ponto em comum: todos falam em nome da cidadania.

Os estudiosos do tema que tratam o terceiro setor como um bloco homogêneo, sem contemplar suas diferenças, acabam sendo induzidos ao erro, à simplificação e estigmatização, fazendo uma leitura reducionista de sua realidade. Assim, vários autores vêem o terceiro setor negativamente, como mais uma forma de exploração da força de trabalho, uma resposta das elites à organização e mobilização sindical e popular dos anos 80, parte das estratégias neoliberais para desobrigar o Estado de atuar na área social. Outros autores, carregam no otimismo acrítico. Proclamam que o terceiro setor é algo realmente novo. Atribuem seu crescimento à falência das políticas estatais na área social, porque o Estado só saberia atuar no nível macro, não conseguindo penetrar nas microesferas da sociedade (respaldando, assim, as teses do "Estado mínimo"); as políticas públicas necessitariam de mediadores para serem efetivas e as entidades do terceiro setor seriam essa mediação. Atuando no nível do poder local, o terceiro setor estaria contribuindo para o desenvolvimento de novas formas de associativismo.

Deve-se destacar que o crescimento do terceiro setor neste final de milênio é um fenômeno do mundo ocidental, e não apenas dos países do Terceiro Mundo. Ele já tem sido caracterizado como um novo setor da economia, o da "economia social". Drucker (1994) constatou que o terceiro setor foi o que mais cresceu, movimentou recursos, gerou empregos, e foi 
o mais lucrativo na economia norte-americana nos últimos vinte anos. Alguns autores, como Offe (1998), diagnosticaram que este setor continuará a ter um grande crescimento e um papel-chave no próximo milênio, no conjunto das relações entre o Estado e a sociedade.

Devemos registrar também que o terceiro setor está participando da revolução na estrutura produtiva da sociedade deste final de século. Como sabemos, essa revolução esvazia e desloca as grandes unidades produtivas e estimula o surgimento de milhares de pequenos negócios na economia informal. Dessa forma, a imensa rede de organizações privadas autônomas, localizadas à margem do aparelho formal do Estado, sem fins lucrativos, mobilizadora de trabalho voluntário, passou a ter uma relação íntima com as mudanças sociais e tecnológicas do final deste século, em duas direções: além de atuar na área da economia informal e gerenciar milhares de empregos voluntários, ela também começa a se fazer presente na economia formal, por meio de parcerias com cooperativas de produção que atuam com demandas terceirizadas, de empresas privadas e de programas apoiados por órgãos públicos. Essas transformações estão afetando significativamente o desenho urbanístico das cidades, interferindo no fluxo de suas vias de comunicação, descentralizando os bolsões industriais, redesenhando os espaços de moradia no intuito de incorporar também o espaço de trabalho.

Salamon \& Anheier (1992, p.15) assim se expressaram sobre a composição e o papel do terceiro setor: "uma virtual revolução associativa está em curso no mundo, a qual faz emergir um expressivo 'terceiro setor' global, que é composto de organizações estruturadas, localizadas fora do aparato formal do Estado, que não são destinadas a distribuir lucros auferidos com suas atividades entre os seus diretores ou entre um conjunto de acionistas; são autogovernadas, envolvendo indivíduos num significativo esforço voluntário".

\subsection{As ONGS Militantes Anos 80 e ONGS Propositivas Anos $90-$} Dois Momentos no Associativismo Brasileiro

As ONGs são a face mais visível do terceiro setor, mas elas são apenas uma das frentes de ações coletivas que o compõe. $E$ as próprias ONGs são também muito diferentes entre si, quanto aos seus objetivos, projetos, formas de atuação e ação coletiva, paradigmas e estilo de participação que adotam; e, fundamentalmente, pressupostos político- 
ideológicos que alicerçam suas práticas (tanto as discursivas como as ações concretas). Neste artigo procuramos demarcar as diferenças entre dois tipos de ONGs nos anos 90: as ONGs oriundas ou herdeiras da cultura participativa, identitária e autônoma dos anos 70-80, às quais denominaremos de militantes; e as ONGs propositivas, que atuam segundo ações estratégicas, utilizando-se de lógicas instrumentais, racional e mercadológica.

No Brasil, nos anos 70-80, as ONGS militantes estiveram por detrás da maioria dos movimentos sociais populares urbanos que geraram um cenário de grande participação da sociedade civil, trazendo para a cena pública novos personagens, contribuindo decisivamente para a queda do regime militar e para a transição democrática no país. Elas contribuíram para a reconstrução do conceito de "sociedade civil" e para a inovação das lutas sociais, inscrevendo como sujeitos de direitos categorias até então esquecidas, criando um novo campo ético-político e cultural por meio de ações coletivas desenvolvidas em espaços alternativos de expressão da cidadania.

As ONGs militantes fundamentaram suas ações na conquista de diversos tipos de direitos, lutaram pela igualdade com justiça social, ajudaram a criar o "discurso da participação popular" como uma necessidade e um componente da democracia. Suas características eram similares aos movimentos populares: enraizamento na sociedade, participação mística estimulada por ícones emblemáticos (como a cruz), crítica e rebeldia, disciplina organizativa, formas de luta social priorizando os espaços na sociedade civil, pouca relação e interlocução com órgãos públicos institucionalizados e uso recorrente de práticas de desobediência civil, ou práticas não circunscritas à legalidade instituída.

Deve-se destacar ainda que uma nova cultura política foi construída a partir daquela herança, em relação ao espaço público e aos temas de interesse coletivo como meio ambiente, saúde, lazer etc., ou temas de interesse de coletivos específicos como os portadores de deficiência física, mental, do vírus da Aids etc. Ou seja, as ONGs cidadãs/ militantes, junto com os movimentos sociais reivindicatórios dos anos 80 , construíram um conjunto de práticas que se traduzem numa cultura de cidadania, algo novo num país de tradição centralizadora, autoritária, patrimonialista e clientelística. Suas ações abriram espaços que demarcaram novos "lugares" para a ação política, especialmente no âmbito do poder local e no meio urbano, na gestão das cidades. 
Paulo Freire afirmou que, quando falamos em nova cultura política, estamos supondo que exista uma velha. Isso obriga-nos a refletir sobre como se constitui o novo. Ele recorda que toda novidade nasce no corpo de uma ex-novidade, que começou a envelhecer. E as novidades não surgem por decreto, pois há uma interligação entre as coisas que vão ficando velhas e as coisas que vão nascendo. (Freire, 1995, p.71) Em nosso caso, a questão a ser pesquisada é quanto à herança daquela cultura política no cenário dos anos 90 .

Nos anos 80, apesar de as ONGs serem, em sua grande maioria, contra o Estado, elas contribuíram para a criação de espaços de interlocução entre o Estado e a sociedade civil. Ao final daquela década as ONGs militantes passaram a enfrentar um dilema: participar ou não das novas políticas sociais estimuladas pelo Estado. O processo Constituinte e a promulgação da nova Constituição brasileira em 1988 representou um divisor de águas, o grande momento de inflexão e de ruptura com a tradição até então predominante: ser contra o Estado. Uma nova concepção de participação iniciou sua construção, unindo a democracia direta à democracia representativa. Tratava-se de participar de um novo momento político, que era a definição das formas de gestão dos equipamentos e serviços, a definição e implantação das leis estaduais e municipais, a construção dos diferentes conselhos e câmaras de interlocução do Estado com a sociedade. Em suma, participar da gestão dos direitos. Não se contentar em estar incluído na lei, via direito adquirido, mas lutar para sua operacionalização e gestão.

O Estatuto da Criança e do Adolescente (ECA), a Lei Orgânica da Assistência Social (LOAS), a reforma sanitária que levou à criação do Sistema Único de Saúde (SUS), a luta pela reforma urbana, as câmaras setoriais da construção civil, as câmaras dos usuários do sistema de transportes coletivos, as câmaras setorias tripartides na indústria automobilística, as experiências de orçamento participativo em diferentes cidades brasileiras, os diferentes conselhos gestores de políticas de habitação, dos direitos da mulher, das pessoas portadoras de deficiências, dos idosos, das escolas, e outras formas de colegiados e estruturas de mediação entre o Estado e a sociedade civil, são exemplos vivos da conquista e da força daquela participação organizada. Trata-se de espaços de negociação e de equacionamento de conflitos de interesses, numa gestão democrática, geradora de uma cultura participativa nova na sociedade brasileira. 
As novas ONGs do terceiro setor não têm perfil ideológico definido, falam em nome de um pluralismo, defendem as políticas de parcerias entre o setor público e as entidades privadas sem fins lucrativos e o alargamento do espaço público não-estatal. A maioria delas foi criada nos anos 90 e não tem movimentos ou associações comunitárias militantes por detrás. Muitas delas surgiram pela iniciativa de empresários e grupos econômicos e seu discurso é muito próximo das agências financeiras internacionais; outras surgiram por iniciativas de personalidades do mundo artístico e esportivo.

As ONGs militantes tornaram-se, nos anos 90 , minoritárias no universo das ações coletivas desenvolvidas nos espaços públicos sem fins lucrativos. Embora elas participem de atividades e eventos conjuntos com as novas ONGs "terceiro-setoristas", elas têm origens e matrizes discursivas nos movimentos populares de base da Igreja, dos anos 7080 , no novo sindicalismo dos anos 70 e na nova esquerda que deu origem ao Partido dos Trabalhadores e a outras alas progressistas de alguns partidos políticos.

O ponto crucial que determinou a mudança no tipo predominante de associativismo nos anos 90 e a crise de identidade e revisão do campo de atuação das ONGs militantes foi o surgimento e/ou reorganização de outras redes associativistas - como a das novas ONGs do terceiro setor (que não querem ser chamadas nem confundidas com as antigas ONGs, autodenominam-se simplesmente como terceiro setor); e as mudanças nas políticas sociais dos Estados nacionais, decorrentes da implantação de um novo modelo de desenvolvimento, de desconcentração de várias atividades estatais na área social, levando à desativação da atuação direta e transferência da operacionalização de vários serviços para o setor privado sem fins lucrativos etc.

Enquanto organizações/empresas que atuam na área da cidadania social, o terceiro setor incorpora critérios da economia de mercado do capitalismo para a busca de qualidade e eficácia de suas ações, atua segundo estratégias de marketing e utiliza a mídia para divulgar suas ações e desenvolver uma cultura política favorável ao trabalho voluntário nesses projetos. Usa a racionalidade instrumental empírica, voltada para a conquista de objetivos imediatos.

O associativismo predominante nos anos 90 não deriva de processos de mobilização de massa, mas de processos de mobilizações pontuais. Qual a grande diferença? No primeiro caso, a mobilização se 
faz a partir de núcleos de militantes que se dedicam a uma causa, seguindo as diretrizes de uma organização. No segundo, a mobilização se faz a partir do atendimento a um apelo feito por alguma entidade plural, fundamentada em objetivos humanitários. Pode ser uma organização internacional (Anistia, Greenpeace), nacional (Ação da Cidadania Contra a Miséria e Pela Vida, a popular Campanha Contra a Fome) ou local. Mas em todos os casos é no local que se desenvolvem as formas de mobilização e sociabilidade. Este tipo de associativismo não demanda dos indivíduos obrigações e deveres permanentes para com uma organização. E a mobilização se efetua independentemente de laços anteriores de pertencimento, o que não ocorre com o associativismo de militância político-ideológica.

\section{A MUDANÇA NO CARÁTER DAS REDES: DA COOPERAÇÃO INTERNACIONAL PARA AS REDES LOCAIS. AS NOVAS RELAÇÕES COM O ESTADO}

É interessante observar que as ONGs predominantes nos anos 80 eram articuladas em redes que se estendiam para além das fronteiras do país, no chamado universo da cooperação internacional. Muitas ONGs viviam exclusivamente com fundos originários daquelas redes internacionais que se entrelaçavam, ONGs do Terceiro Mundo com as do Primeiro Mundo. Em sua maioria, as ONGs tinham matrizes cristãs ou humanistas, e em alguns casos, inspiração social-democrata. No Brasil, elas se relacionavam com outras ONGs, com sindicatos, movimentos sociais, partidos, igrejas (católicas e protestantes) e com empresas.

Nos anos 90 a forma de processar a ajuda e cooperação internacional se altera em linhas gerais. Apesar de existirem ainda muitas entidades de cooperação internacional não-governamentais que se relacionam diretamente com entidades não-governamentais brasileiras, o que passou a predominar são programas desenvolvidos com o apoio de agências financiadoras internacionais, a partir de acordos e empréstimos feitos ao governo brasileiro. O programa de requalificação de trabalhadores, desenvolvido pelo governo federal em parceria com sindicatos, movimentos e entidades do terceiro setor, e governos estaduais, é um dos exemplos. Algumas ONGs do terceiro setor geram receitas via rendas auferidas na prestação de serviços. 
A nova conjuntura propiciou a criação de entidades com fortes vínculos com os governos locais, e menos articuladas com a rede de cooperação internacional de matriz religiosa. Essas mudanças têm sentido econômico e político profundos, pois as entidades do terceiro setor entram no circuito das políticas de empréstimos ao país, integraramse ao sistema e ao modelo de desenvolvimento da nação. Do ponto de vista político, as ações das entidades do terceiro setor passaram a apresentar um perfil em que há consonância com as regras do status quo nacional, ao contrário do que ocorria nos anos 80 , quando a maioria das ONGS nacionais era crítica ao governo brasileiro e se articulava às ONGs internacionais, poderosas entidades supra-nacionais, experts na crítica e na denúncia das políticas locais excludentes.

No nível do governo federal, a contribuição estatal ao terceiro setor tem sido na área jurídica, de regulamentação de novas regras que vieram a criar um novo marco legal para o trabalho voluntário. Em março de 1999 foi aprovada a lei que dispõe sobre a qualificação de pessoas jurídicas de direito privado sem fins lucrativos como Organizações da Sociedade Civil de Interesse Público (OSC-IP), também conhecida como Lei do Terceiro Setor ou Lei das ONGs. Ela normatiza e cria novos tipos de relações de trabalho, institui e disciplina as relações e o termo das parcerias, aborda a questão do voluntariado e trata da remuneração dos dirigentes. A lei trata também da prestação de serviços não-remunerados por períodos superiores a noventa dias e que não criam vínculos empregatícios, e, conseqüentemente, desobrigam dos encargos trabalhistas. É interessante relembrar que, no discurso dos defensores desse tipo de trabalho, a independência em relação ao sindicato é bastante destacada, porque o trabalho voluntário não possui, até o momento, redes de articulações ou de pressões.

As políticas de desativação de atividades do Estado e transferência para setores da iniciativa privada encontraram em muitas das novas ONGs do terceiro setor interlocutores ávidos em implementar as novas orientações. Rapidamente alteraram-se os discursos, passando-se a enfatizar as políticas de parceria e cooperação com o Estado, destacandose uma nova era onde não se trata mais de dar costas ao Estado ou apenas criticá-lo, mas de alargar o espaço público no interior da sociedade civil, democratizar o acesso dos cidadãos a políticas públicas e contribuir para a construção de uma nova realidade social, criando canais de inclusão dos excluídos do processo de trabalho. As ONGs passarão a atuar não 
apenas na geração de empregos e oportunidades de trabalho temporário, sem vínculo empregatício, sob a forma de cooperativas, onde a renda é gerada pela quantidade produzida. Passarão a atuar também no âmbito da requalificação dos trabalhadores, patrocinando cursos de curta duração para desenvolver novas habilidades ou alternativas para aqueles que estão sendo excluídos do mercado de trabalho - por obsolescência de suas funções ou introdução de novas tecnologias, ou simplesmente sendo demitidos devido a programas de redução de custos.

As ONGs, através do terceiro setor, entraram para a agenda das novas políticas sociais. Na educação, por exemplo, atuarão em programas com meninos e meninas nas ruas, jovens/adolescentes em situação de risco em face do mundo das drogas, treinamento e capacitação de profissionais da rede escolar, creches e/ou escolas de educação infantil, campanhas e programas de educação para civilidade no trânsito, prevenção de doenças e da Aids etc. As campanhas de alfabetização e de ensino a distância, as jornadas de resgate da identidade cultural dos negros, a luta pela demarcação das terras indígenas, a construção de fóruns de debates sobre direitos humanos e cidadania, a institucionalização da política de conselhos: crianças e adolescentes, mulheres, idosos, escolares; o surgimento de inúmeras entidades ambientalistas voltadas para a defesa, conservação e/ou restauração do meio ambiente, dos animais e do patrimônio histórico e cultural da sociedade como um todo, são algumas das outras iniciativas que têm sido empreendidas pelas entidades do terceiro setor.

O caráter da maioria das ações das novas entidades do terceiro setor, especialmente das prestadoras de serviços na área social - apesar de todos os aspectos meritórios de suas ações no combate à pobreza é emergencial. As ações não se destinam a acabar com os problemas, ou resolvê-los, mas a equacioná-los de uma forma socialmente aceitável, integrando as clientelas/alvos em programas sociais de caráter compensatório. Fazem isso por meio de atuações de caráter pontual, de curta duração, e dependentes da renovação contínua dos convênios, acordos etc. Ou seja, as ações são dependentes das verbas e fundos advindos das parcerias com os governos e outras entidades que, por sua vez, dependem da liberação de verbas e empréstimos dos pacotes internacionais. Resulta disso uma teia de articulações, continuamente realimentada por objetivos/alvos que são paliativos em face dos problemas sociais em questão. Essas ações de auto-ajuda, quando levadas

Rev. Mediações, Londrina, v. 5, n. 1, p. 11-40, jan./jun. 2000 
a efeito por entidades de perfil ideológico mais conservador, podem vir a alterar completamente o sentido e o caráter das ações coletivas, deslocando a responsabilidade coletiva do Estado para os indivíduos, num estilo meramente assistencialista e compensatório.

\section{TERCEIRO SETOR E MOVIMENTOS SOCIAIS}

As associações do terceiro setor estão passando a ocupar o papel que antes era desempenhado pelos sindicatos e pelos partidos políticos. O novo associativismo do terceiro setor tem estabelecido relações contraditórias com o "antigo" associativismo advindo dos movimentos sociais populares (na maioria urbanos) dos anos 70 e 80 . Enquanto estes últimos fizeram da política seu eixo básico de articulação e identidade, atuando por meio de reivindicações por direitos (sociais, políticos, econômicos, culturais, por cidadania de forma geral), e eram amalgamados pelas ideologias da esquerda (num grande espectro de matizes e tendências), o associativismo do terceiro setor é pouco ou nada politizado, na maioria das vezes avesso às ideologias e integrado às políticas neoliberais. De certa forma, o terceiro setor faz coro com as políticas neoliberais conservadoras, pois algumas de suas entidades desqualificam tudo o que foi ou era progressista nos anos 80 como arcaico e nãomoderno.

Mas o novo associativismo é contraditório, como já foi dito. Ele é herdeiro e absorveu vários aspectos do associativismo militante anterior. Isso tem possibilitado, em alguns estados, cidades ou regiões, onde há propostas e gestões administrativas com visões progressistas, o desenvolvimento de espaços novos para os atores organizados institucionalmente, como nas experiências de gestão com representação popular e com o orçamento participativo, em várias cidades brasileiras. Esta nova forma está alterando a gestão das cidades, porque a ação dos novos atores sociais tem ultrapassado os particularismos geográficoterritoriais, presentes na organização tradicional da administração da cidade e na organização das entidades populares, e tem se organizado setorialmente ao redor dos grandes eixos temáticos da cidade: saúde e saneamento, educação e cultura, trabalho e centros de geração de rendas etc. Eles atuam através de comissões plenárias que se dividem em serviços (para a manutenção da rede de serviços urbanos) e novas 
intervenções (por meio de novos instrumentos urbanísticos que procuram ser contra a exclusão social). A descentralização política da cidade institui uma esfera pública não-estatal. Trata-se da construção de novas relações sociais fundadas em uma nova ética e numa nova cultura política, que redefine a cidadania e cria uma nova esfera pública, de controle nãoestatal. E construir uma esfera pública não-estatal significa criar instituições voltadas para a produção e reprodução de políticas públicas, que não são controladas pelo Estado mas têm um caráter indutivo, fiscalizador e controlador do Estado. (vide Genro \& Souza, 1997)

As ONGs - novas e antigas — têm tido muita desenvoltura para participar nos locais onde se instauraram administrações eleitas com o apoio dos partidos oposicionistas e foram implementadas políticas participativas locais. Nesses casos elas reelaboraram seus discursos e práticas em direção a uma cultura propositiva que busca tornar as cidades sustentáveis e mais justas.

Segundo alguns autores, nos anos 90 vive-se não apenas uma crise financeira do Estado mas uma fase de redefinição e modernização de sua estrutura e aparelhos, dado que sua forma clássica de dominação está esgotada. A emergência de cidadãos da sociedade civil intervindo nas políticas públicas gerou novos atores com capacidade para desenhar o percurso da política, intervir no Estado, criando uma nova forma de representação que está modernizando o Estado. Essa interpretação, advinda de setores da nova esquerda brasileira, não se fixa apenas na leitura do maquiavelismo estatal neoliberal mas destaca o lado positivo da "revolução" que está se operando em algumas administrações no Estado brasileiro.

O terceiro setor estrutura-se basicamente a partir de organizações institucionalizadas e articula-se com alguns tipos de movimentos sociais, de caráter mais propositivo e menos reivindicativo. Registra-se que em várias áreas do terceiro setor não existem sindicatos ou associações de trabalhadores, por se tratar de áreas de prestação de serviços públicos, desenvolvidos por entidades compostas com um corpo de recursos humanos basicamente de trabalho voluntário. E quando o trabalho é assalariado, trata-se de contrato precário, por tempo determinado, segundo projetos específicos. Com isso, essas entidades do terceiro setor não encontram resistência de grupos organizados e implementam diretrizes das políticas sociais governamentais sem problemas. O que ocorre é uma competição entre as entidades pelo acesso às verbas destinadas aos 
programas, obscurecendo por completo a própria natureza dos programas (em relação ao seu caráter, mais ou menos emergencial; progressista ou conformista; etc.). Em época de desemprego, qualquer frente de trabalho assistencialista encontra respaldo e apoio popular.

\section{CULTURA POLIITICA E ASSOCIATIVISMO NO TERCEIRO SETOR}

Já explicitamos o nosso entendimento sobre cultura política em trabalhos anteriores (Gohn, 1992a; 1992b; 1997a) tomando como referência os estudos de Thompson (1979) e Bobbio et al. (1991). O primeiro, "elaborou várias contribuições sobre a natureza, a força social e a construção da cultura política enquanto processo político e cultural". (Gohn, 1997a, p.259) Bobbio et al. (1991, p.306) definiram cultura política como "o conjunto de atitudes, normas e crenças mais ou menos partilhadas pelos membros de uma determinada unidade social". Os autores destacam ainda que não devemos ver a cultura política como algo homogêneo; ela é composta por um conjunto de subculturas presentes nas atitudes, normas, valores etc.

Portanto, falar de cultura política é tratar do comportamento de indivíduos nas ações coletivas, é tratar dos conhecimentos que os indivíduos têm a respeito de si próprios e de seu contexto, é tratar dos símbolos e da linguagem utilizados, bem como das principais correntes de pensamento existentes. Mas é muito complicado falar em cultura política de forma isolada do contexto histórico e de outros conceitos de apoio. Isso porque cada época histórica engendra determinada cultura política, segundo os valores e crenças que são resgatados ou construídos, num universo dos temas e problemas com os quais homens e mulheres defrontam-se naquele momento histórico. Os conceitos de apoio são cidadania, direitos humanos, identidade cultural, participação sociopolítica etc.

Nos últimos dez anos a cultura política voltou a ser um conceitochave em todas as áreas das ciências sociais e não apenas na ciência política. Uma das explicações pode ser dada pela importância que a cultura passou a ter nas análises dos cientistas sociais, enquanto eixo paradigmático fundamental nas explicações sobre as ações humanas vivenciadas na realidade, em detrimento das análises econômicas e políticas das décadas anteriores. Os meios de comunicação também 
passaram a ter papel central na sociedade e na política, obrigando os analistas a recorrer ao estudo dos códigos linguísticos e audiovisuais, aos processos interativos via multimídia, para poder compreender as novas realidades virtuais etc.

Novas abordagens sobre a cultura política têm sido elaboradas, resultando numa teoria neoculturalista da política. Destaca-se que as referências e preferências nos comportamentos humanos não são apenas as herdadas, mas, principalmente, as aprendidas. A cultura política vista não apenas como legado histórico mas como prática viva e atuante redefine-a como algo que resulta da interação permanente entre valores antigos (que persistem por meio das tradições) e valores novos (que são agregados ao repertório das pessoas pelo fato de elas viverem num mundo globalizado, competitivo e em busca de contínuas inovações que produzam diferenciais entre os indivíduos). Isso tudo faz com que a cultura política seja resultado de um processo que a constrói cotidianamente, por meio de um jogo de reciprocidade. Os atores sociais possuem suas crenças e valores, mas reagem em face dos acontecimentos da política segundo a interpretação que captam das ações dos atores do mundo da política oficial, governamental. Esta interpretação é usualmente mediada pelos meios de comunicação, de tal forma que, para se entender a cultura política de um grupo social, ou de seus atores em particular, temos que decodificar o conjunto de significados atribuídos ou construídos - no universo do imaginário e das representações sociais daqueles grupos ou indivíduos.

Posta nossa visão sobre o papel da cultura política na atualidade, indagamos: o que tem sido mais forte no dia-a-dia dos participantes das novas formas de associativismo que caracterizamos anteriormente? A herança dos anos 80 , em seu sentido participativo, militante e crítico, decorrente das práticas dos movimentos sociais em geral e dos populares em particular, ou o sentido atual, pragmático, das entidades do terceiro setor? Trata-se de indagar também sobre o tipo de práticas pedagógicas e educativas que tinham e qual tipo exercitam atualmente. Qual a natureza do processo de aprendizagem nos dois casos. Isso porque a educação gerada no aprendizado da vida e experiência cotidiana está intimamente associada ao tipo de cultura política que os indivíduos e grupos desenvolvem. Os indivíduos escolhem, optam, posicionam-se, recusamse, resistem ou alavancam e impulsionam as ações sociais em que estão envolvidos segundo a cultura que herdaram do passado e na qual estão 
envolvidos no presente. Eles criam novos repertórios discursivos a partir da fusão/confrontação: passado e presente.

$\mathrm{Na}$ caracterização que fizemos sobre o novo associativismo do terceiro setor observa-se - em sua ala de caráter mais propositivo, que só quer ser denominada como terceiro setor e tem relações com as "empresas cidadãs" ou com as grandes corporações que lhes patrocinam subsídios - um grande número de entidades novas, compostas de dirigentes e participantes sem experiência associativa/comunitária anterior, ou qualquer tipo de militância político-partidária ou sindical. Eles trabalham a partir dos valores de uma cultura política propositiva, baseada numa lógica que não possui muitos elementos de ordem críticodemandatária, de pressão-reivindicativa. Eles se colocam na esfera pública numa perspectiva mais de associacionismo, de colaboracionismo com quem quer que atuem. Nesse sentido, o tipo de cultura política que gera tende a reforçar as políticas assistenciais, integradoras e compensatórias. E os repertórios discursivos que são construídos passam pelo filtro da mídia, porque é a mídia que legitima e confere notabilidade às ações. Ter uma reportagem na Globo, no canal Futura, ganhar alguma manchete ou qualquer tipo de reportagem nos jornais e revistas de grande circulação nacional passa a ser curriculum para aquelas entidades. As ações das entidades não são julgadas ou avaliadas pelo que elas fazem mas pelo que outros falam delas.

As ONGS e outras entidades deste complexo e contraditório cenário do terceiro setor atual, originárias do ciclo militante, participativo/reivindicativo/contestador, apresentam um tipo de cultura política totalmente distinto. Podemos ver em suas práticas um tipo de cultura política semelhante ao que Morfin (1994) caracterizou, a saber: "como o conjunto de significados e valores com o que se constrói o sentido da comunidade política, da tomada de decisões para o bem de todos, através dos conflitos inerentes à coexistência e convivência humana. Esta cultura abrange e se sustenta na cultura dos direitos humanos e políticos dos membros de uma comunidade. Para que este conjunto de significados seja construído, há dois momentos: primeiro constitui-se um credo, um conjunto de certezas assumidas como válidas. Em segundo lugar, para que este conjunto de significados e valores opere na tomada de decisões, requer-se que a comunidade se aproprie deles, como um desígnio, com uma vontade política de ir a algum lugar. (...) Estes fatores seriam os impulsionadores das discussões e busca de 
soluções de um determinado grupo". (Morfin, 1994, p.468) Observa-se que aqui a cultura política não é uma determinação passiva que explique os comportamentos humanos, mas uma força ativa, moldada pelos direitos humanos, pelo desejo de busca de soluções. E por ser ativa requer aprendizado, confronto entre o velho e o novo.

As ONGS militantes passaram ao longo dos anos 90 um tanto quanto desarticuladas porque o novo, o propositivo, teve que ser absorvido e assimilado. O resultado começa a aparecer ao final desta década, onde voltam a pipocar ações associativas nos quatro cantos do país, unindo o militante com o propositivo. E o repertório discursivo começa também a ser reconstruído. Das demandas gerais, e um tanto quanto abstratas de direitos e cidadania, passa-se para a operacionalização daqueles sentidos em conteúdos específicos. Trata-se de demandar/ participar da construção de políticas públicas para as crianças, para as mulheres, os índios, os sem-terra, os jovens e adolescentes. E o espaço por excelência onde isso está ocorrendo são os conselhos, conforme caracterizamos anteriormente.

A educação está também entrando na agenda das entidades mais críticas com um sentido renovado, aliada à questão da cultura política. A educação é um processo que requer a integração de conhecimentos com habilidades, valores e atitudes e como tal está associada ao desenvolvimento da cultura política. Juntas, educação e cultura política têm a finalidade de ser instrumento e meio para compreender a realidade e lutar para transformá-la.

Nos anos 90, a retomada dos estudos na área da psicologia social e o interesse sobre como operam os mecanismos dos processos cognitivos dos indivíduos e como eles influenciam as atitudes e os comportamentos das pessoas têm levado a se eleger a cultura política como o espaço de fusão entre a tradição e a inovação. Disso resulta que outras formas de apreensão da cultura política - de ordem mais qualitativa — foram produzidas, gerando abordagens que privilegiam não as escalas de atitudes no comportamento dos indivíduos, mas a identidade criada em um coletivo de atores sociais, a partir do conjunto de valores e representações simbólicas que eles têm sobre a realidade social. Nessa linha a cultura política passa a ser vista como "um conjunto de códigos que permite o estabelecimento de relações políticas entre indivíduos e grupos, e que, portanto, tem a ver com a dimensão subjetiva da vida pública e com a interpretação e produção de sentido". (Ponte, 1992, p.165) 
A importância do papel da cultura política passou a ser atribuída à possibilidade que esta oferece para explicar a ação política dos indivíduos nos grupos sociais, o comportamento político dos indivíduos como seres políticos, no sentido aristotélico, e não apenas em relação às instituições políticas e/ou aos governantes, em especial no momento do voto. Com isso a ênfase desloca-se das atitudes e opiniões dos indivíduos isolados para os indivíduos como membros participantes de grupos, de coletivos sociais com uma identidade: sem-terra, negro, mulher, defensor de causas ambientalistas etc.

\section{CONCLUSÃO: EXCLUSÃO E PARTICIPAÇÃO}

Seguindo um dos objetivos deste texto, que é entender a problemática da participação social das classes populares em movimentos sociais, ONGs ou entidades do terceiro setor na sociedade brasileira atual, concluímos que, independente da forma como denominamos o processo de exclusão social, com a economia globalizada este final de século se encerra com grandes mudanças no mundo do trabalho, e essas mudanças estão afetando todo o modo de vida das pessoas. As leis que estão sendo revistas fazem parte de um sistema de seguridade social, previdenciária, estatal, fruto de séculos de lutas e conquistas dos trabalhadores. A origem do processo de exclusão é dada por três ordens básicas de fatores: pelas inovações tecnológicas que eliminam determinadas profissões ou funções na cadeia produtiva; pelas reengenharias administrativas no mercado de trabalho, reduzindo cargos, hierarquias e funções; e pelas reformas estatais nas leis do país que possibilitam a flexibilização e a desregulamentação do sistema de normas e contratos sociais. Sabemos que um dos principais resultados do processo de exclusão social é o aumento do desemprego. Na América Latina, a exclusão social sempre foi a regra dominante para o conjunto das camadas populares, sem escolaridade e com inserções pontuais no setor terciário atrasado da economia de serviços. No Brasil, a exclusão social está atingindo mais os setores da classe operária com carteira assinada. As camadas médias estão assustadas e desorganizadas politicamente. Todos estão buscando qualificar-se por meio de novos cursos na educação formal ou não-formal, porque o discurso dominante é este: requalificação profissional. As elites locais reelaboram suas 
estratégias de atuação buscando parcerias nas novas políticas públicas. O capital financeiro internacional determina as regras do jogo econômico e as ênfases das políticas públicas. Os movimentos sociais populares, bastante desmobilizados nos anos 90 , começam a se organizar em outros formatos de lutas, menos reivindicativos e mais propositivos.

Em resumo: estamos vivendo um novo momento na trajetória do associativismo brasileiro. A grande maioria das ONGs está mudando de nome para simplesmente terceiro setor. As novas redes associativistas estão contribuindo para o que já foi denominado como empowerment (empoderamento) dos setores populares em nossa sociedade. Um dos problemas dessas instituições é que seu impacto na realidade é lento e muito pontual e os problemas sociais são graves e necessitam respostas urgentes. Por isso as novas ONGs, de perfil mais agressivo, estruturadas com o apoio de grandes grupos ou companhias empresariais, atuando nas franjas da nova economia social, segundo regras e critérios de racionalidade de uma economia de mercado, ainda que sem fins lucrativos, tendem a predominar sobre as ONGs que trabalham com maior ênfase apenas na capacidade da sociedade para se organizar e defender seus interesses, na construção de novos atores sociais que representam distintos interesses e atuam em defesa da cidadania. Elas trabalham e produzem capitais sociais distintos.

O terceiro setor não substitui a forma movimento social - típica das ações coletivas de protesto, resistência e lutas que vigorou nos anos 80 (até porque esta forma ainda é muito forte na área rural). Ele se alimenta das conquistas dos movimentos sociais, principalmente as que foram consolidadas no plano da lei. Mas uma parcela dele retraduziu as práticas daqueles movimentos para práticas de cunho despolitizado e reelaborou os objetivos das ações coletivas, de lutas contra a exclusão social gerada pelo modelo econômico para frentes de trabalho que buscam a inclusão e a integração social no modelo econômico atual, nos moldes propostos pelo governo e agências de financiamento. Portanto, alterou-se o sentido das ações coletivas de participação da população. Com isso temos a chave necessária para entender o processo de desmobilização social que ocorreu. Entretanto, esse novo sentido, embora tenha confundido muitos, não impediu a capacidade daqueles setores que acumularam práticas e experiências nos anos 80 , de se reorganizarem na última década, defenderem seus interesses e proporem formas de gestão e políticas que se orientam em direção a uma ampliação 
da esfera pública e da cidadania. Resulta disso tudo um cenário contraditório onde convivem a busca da integração mediante a participação comunitária e a busca de transformação social através da mudança dos eixos, diretrizes e modelo de desenvolvimento que têm sido dados à sociedade brasileira até o momento pelas atuais políticas públicas nacionais.

Se rememorarmos o famoso debate que ocorreu nos anos 80 , nos Estados Unidos e na Europa, sobre o significado e o sentido dos movimentos e ações coletivas dos anos 60-70 e 80, que resultou em duas posições, os defensores da tese de que os movimentos eram ações estratégicas de determinados grupos sociais e os que postulavam a tese de que os movimentos eram lutas e ações para a construção de novas identidades (sociais, culturais e políticas), observamos que, nos anos 90, no Brasil, houve na realidade uma fusão dos dois sentidos, com um certo predomínio das ações estratégicas. As próprias alas progressistas das ONGs afirmam, atualmente, que já não bastam princípios gerais e boas análises da sociedade. É necessário boas análises para armar estratégias políticas viáveis segundo a correlação de forças políticas presentes na conjuntura.

\section{NOTAS}

I A Teologia da Libertação foi desenvolvida na América Latina por F. Gutierrez e no Brasil destacaram-se os irmãos Leonardo e Clodóvis Boff. A partir das orientações advindas do Concílio Vaticano II, de 1964, e do Congresso de Medellín, na Colômbia, em 1968, a Teologia reorganizou as práticas religiosas católicas. Elas foram adaptadas ao meio popular e redefiniram algumas concepções. Passou-se a preconizar que os indivíduos deveriam lutar pela justiça social enquanto vivos, não serem passivos face às injustiças. $\mathrm{O}$ cotidiano das pessoas passou a ser discutido à luz dos ensinamentos da Bíblia. Alguns princípios da análise marxista relativos às estruturas de dominação, influenciaram e foram incorporados à Teologia da Libertação.

2 Na realidade, o ano de 2000 marca o retorno dos movimentos sociais também no exterior. Um novo tipo de movimento social ganha força: contra a globalização. Desta vez eles passam a ser promovidos por uma gama imensa de novos grupos libertários envolvendo punks, darks, velhos hippies etc. 
BOBBIO, N.; MATTEUCCI, H.; PASQUINO, G. Dicionário de política. Brasília: Editora da UnB, 1991.

CHIAvenATO, Júlio J. As lutas do povo brasileiro. São Paulo: Moderna, 1988.

DRUCKER, Peter F. Administração de organizações sem fins lucrativos. São Paulo: Pioneira/Fund. Vanzolini, 1994.

FREIRE, Paulo. A constituição de uma nova cultura política. In: VILLAS-BOAS, R. \& TELLES, V.S. Poder local, participação popular, construção da cidadania. São Paulo: Instituto Cajamar/Instituto Pólis/FASE/RBASE, 1995. p.71-74.

GENRO, Tarso \& SOUZA, Ubiratan. Orçamento participativo: a experiência de Porto Alegre. São Paulo: Ed. Fund. Perseu Abramo, 1997.

GIDDENS, Anthony. Sociology. 2.ed. Oxford: Polity Press, 1993.

GOHN, M. da G. Movimentos sociais e educação. São Paulo: Cortez, 1992a.

. Conam, Anampos e Pro-Central dos Movimentos Populares: três formas de cultura política. In: Movimentos populares urbanos: crise e perspectivas. Porto Alegre: FASE/CIDADE, 1992b. p.13-38.

História das movimentos e lutas sociais. São Paulo: Edições Loyola, 1995.

. Teoria dos movimentos sociais. São Paulo: Edições Loyola, 1997a.

. Os sem-terra, ONGs e cidadania. São Paulo: Cortez, 1997b.

. Educação não-formal e cultura política. São Paulo: Cortez, 1999.

MORFIN, L. Educación y cultura política. In: ALONSO, J. Cultura política e educación cívica. México: Universidad Autonoma do México, 1994. p.465-480.

OFFE, Claus. O novo poder. Veja, p.11-13, 8. abr. 1998. Entrevista concedida a Thomas Traumann.

PAOLI, M. Célia. Movimentos sociais no Brasil: em busca de um estatuto político. In: HELLMAN, Michaela. Movimentos Sociais e democracia no Brasil. São Paulo: Marco Zero, 1995. p.24-55.

PONTE, V.M.D. Contexto e mudança na cultura política mexicana. In: Lua Nova, São Paulo, CEDEC, n.26, 1992. p.163-180.

SILVELRA, Ricardo. O movimento operário e os "novos" movimentos sociais. In: TOMAZI, N.D. (coord.) Iniciação à sociologia. São Paulo: Atual, 1993. p.222-250.

SOUZA, Cláudia M. \& MACHADO, Ana C. Movimentos sociais no Brasil contemporâneo. São Paulo: Ed. Loyola, 1997.

THOMPSON, E.P. Tradición, revuelta y consciencia de clase. Barcelona: Editorial Crítica/Grijalbo, 1979.

TOURAINE, Alain. Palavra e sangue. Campinas: Ed. UNICAMP, 1989. 
Este trabalho objetiva realizar um breve balanço das lutas sociais que a sociedade brasileira tem empreendido ao longo da história do país, em especial as desenvolvidas pelas classes populares. A partir da delimitação conceptual do que são movimentos sociais realiza-se, num primeiro momento, um mapeamento dos principais movimentos e lutas sociais ao longo dos últimos séculos. Num segundo momento, analisa-se a contemporaneidade dos anos 90 . Busca-se entender a problemática da participação social na virada do milênio, numa conjuntura marcada pela emergência de novas formas de associativismo tais como as ONGs e outras entidades do terceiro setor.

Palavras-chave: movimentos sociais; organizações não-governamentais; terceiro setor.

\section{ABSTRACT}

This paper aims to provide a brief but critical account of the social struggles carried on by the Brazilian society throughout the history of the country, specially the ones developed by the lower classes. Based on the conceptual delimitation of what social movements are, the article traces the main social movements and struggles of the last centuries. After this, it analyses the contemporaneity of the 1990s. The article also tries to provide an explanation for the issue of social participation in the turn of the millennium, in a state of affairs that is marked by the emergence of new forms of association, such as the non-governmental organisations and other entities from the third sector.

Key words: social movements; non-governmental organisations; third sector:

Maria da Glória Gohn é professora titular da Faculdade de Educação da Unicamp e coordenadora do Grupo de Estudos sobre Movimentos Sociais, Educação e Cidadania (GEMDEC). 